\title{
Response of Mungbean Root System Architecture to Phosphorus Application Methods ${ }^{+}$
}

\author{
Vijaya Singh ${ }^{1, *}$, Marisa Collins ${ }^{1}$, Colin Andrew Douglas ${ }^{2}$ and Michael Bell ${ }^{1}$ \\ 1 School of Agriculture and Food Sciences, The University of Queensland, Gatton, QLD 4343, Australia; \\ v.singh@uq.edu.au (S.V.); m.collins@uq.edu.au (C.M); m.bell4@uq.edu.au (B.M.) \\ 2 Department of Agriculture and Fisheries, Hermitage Research Facility, 604 Yangan Road, Warwick, QLD \\ 4370, Australia; Col.Douglas@daf.qld.gov.au \\ * Correspondence: v.singh@uq.edu.au \\ + Presented at the third International Tropical Agriculture Conference (TROPAG 2019), Brisbane, Australia, \\ 11-13 November 2019.
}

Published: 7 April 2020

\begin{abstract}
In recent years phosphorus application methods have become an important management strategy for optimising the uptake of the immobile nutrient phosphorus (P). Root system architecture (RSA) could play a particularly important role in the uptake of $P$ by grain legumes, due to their relatively coarse root systems. The objective of this study was to understand the response of mungbean root systems to $P$ application methods. Four mungbean varieties were grown in purposebuilt soil filled root chambers that received five P application methods. Phosphorus treatments consisted of a control (no application of P) compared with $30 \mathrm{mg} \mathrm{P} / \mathrm{kg}$ soil throughout the soil volume (high $P$ treatment) or restricted to $10 \mathrm{~cm}$ deep layers in the topsoil or in a layer from $20-30 \mathrm{~cm}$ deep. A fifth treatment consisted of the same amount of $\mathrm{P}$ as applied in deeper dispersed layer applied in a concentrated band at $25 \mathrm{~cm}$ depth. After 50 days of growth, plant were destructively harvested and shoot and root parameters were measured. Mungbean varieties responded differently to $\mathrm{P}$ application methods, with Jade and Berken varieties showing greater root proliferation at depth and greater shoot growth in response to banded and deeper dispersed $\mathrm{P}$ applications, relative to the late maturing variety Putland. Shallow dispersed $\mathrm{P}$ and the no-P control both resulted in poor root growth in all the genotypes except Celera II, which did not respond to $\mathrm{P}$ application from any placement strategy. Results suggest that $\mathrm{P}$ application strategies may need to vary with variety to maximize the uptake of $P$.
\end{abstract}

Keywords: phosphorus acquisition; mungbean varieties; root system architecture; phosphorus application methods; deep banding

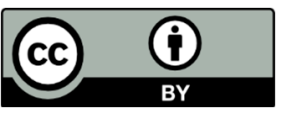

(C) 2020 by the authors. Licensee MDPI, Basel, Switzerland. This article is an open access article distributed under the terms and conditions of the Creative Commons Attribution (CC BY) license (http://creativecommons.org/licenses/by/4.0/). 